\title{
Narrative Discourse Analysis of "Hojarat" Surah: A Faircloughian Study
}

Ali Asvadi

Assistant professor in Arabic language and literature at Kharazmi University. (Corresponding Author)

Soudabeh Mozaffari

soud42_moz@khu.ac.ir

Assistant professor in Arabic language and literature at Kharazmi University.

Mahrokh Gohar Rostami

mah.goharrostami@gmail.com

M.A Student in Arabic language and literature at Kharazmi University.

\begin{abstract}
Critical Discourse Analysis (CDA) is a significant sub-discipline of Discourse Analysis. This approach takes its lead from the philosophical ideas propounded by Michel Foucault, Sigmund Freud, and Karl Marx. Norman Fairclough, an eminent theorist of CDA, attempts to link linguistic features to social issues so that linguists find it necessary to engage with social problems. According to Fairclough, discourse analysis can be performed at three levels: description, explanation, and interpretation. In the holy Quran and Surahs like "Hojarat", there are abundant conceptual signs which are used to modify social norms. The interpretation level in CDA deals with the relationship between dominant social discourse with different social discourses. Drawing on the description and explanation levels of CDA, this study attempt to develop a critical framework to analyze social discourses in "Hojarat" Surah. It is proposed that the narrative discourse at the education axis in "Hojarat" Surah is in line with social discourses which seek to define Islamic value system.
\end{abstract}

Key words: The Holy Quran, Surah Al-Hujurat, Discourse, Faircloughian Study, Critical Analysis, Studies in Arabic Narratology.

Citation: Asvadi, Ali; Mozaffari, Soudabeh; Gohar Rostami, Mahrokh, A. Autumn \& Winter (2020-2021). Narrative Discourse Analysis of "Hojarat" Surah: A Faircloughian Study. Studies in Arabic Narratology, 2(3), 30-52. (In Arabic)

Studies in Arabic Narratology, Autumn \& Winter (2020-2021), Vol. 2, No.3, pp. 30-52 Received: July 24, 2020; Accepted: March1, 2021

CFaculty of Literature \& Humanities, University of Kharazmi and Iranian Association of Arabic Language \& Literature. 


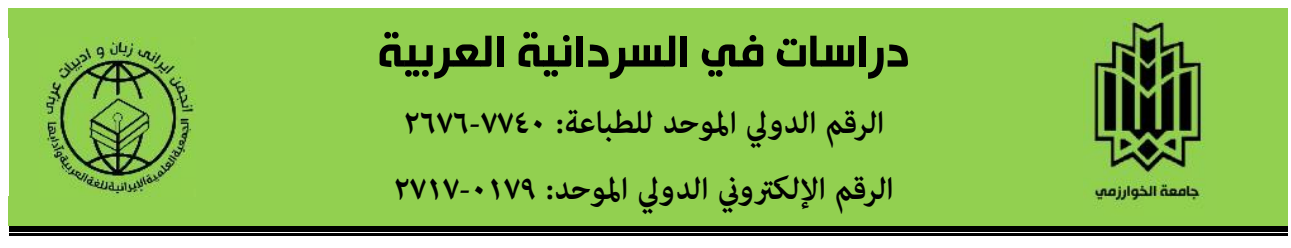

\section{تحليل خطاب السرد القرآني لسورة الحجرات وفق نظرية نورمن فركلاف}

asvadi@khu.ac.ir

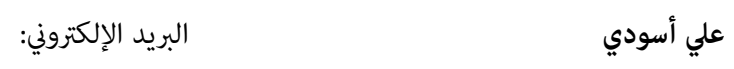

أستاذ مساعد في قسم اللغة العربية وآدابها بجامعة الخوارزمي،ايران،(الكاتب المسؤول) soud42_moz@khu.ac.ir

$$
\text { سودابه مظفري } \quad \text { أستاذة مساعدة في قسم اللغة العربية وآدابها بجامعة الخوارزمي،ايران، }
$$

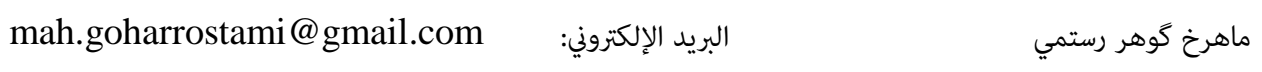
طالبة مرحلة ماجستير في قسم اللغة العربية وآدابها بجامعة الخوارزمي، البردي،

الإحالة: أسودي، علي؛ مظفري، سودابه؛ كَهر رستمى، ماهرخ. خريف وشتاء (·r.r(r.r.r). تحليل خطاب السرد القرآني لسورة الحجرات وفق نظرية نورمن فركلاف، دراسات في

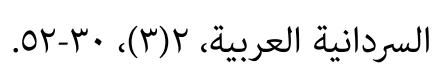

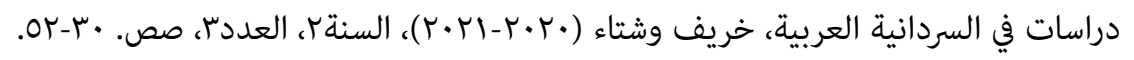

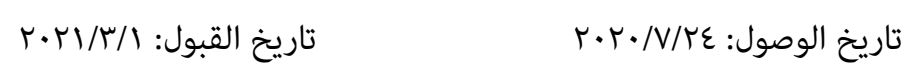

ه كلية الآداب والعلوم الإنسانية بجامعة الخوارزمي والجمعية العلمية الإيرانية للغة العربية

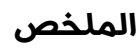

يعد التحليل النقدي للخطاب من أحدث المناهج النقدية، تأثر هذا المنهج من وجهات نظر ميشل فوكو وفرويد وماركس فلسفيًا. إنه ينوي ربط الأشكال التعبيرية بالقضايا 
الاجتماعية ونقلها إلى النقطة المطلوبة. تعتبر مقاربة فركلاف ذات المستويات الثلاثة من أوصاف وتفاسير وشروح مفيدة وناجحة في هذا الجانب. من جانب آخر حاول القرآن الكريم تعديل المهارسات الاجتماعية من خلال استخدام الإثارات والرموز

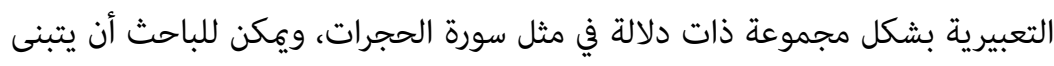
نموذج فركلاف في دراسة السور القرآنية، فمن خلال تحليل البنية النصية مثل الكلمات والجمل على مستوى الوصف وتطبيقه على السياق في مستوى تفسير الخطاب الحاكم، هردي،

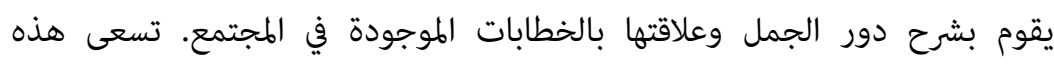
الدراسة معتمدة على المنهج الوصفي التحليلي إلى توفير إطار لتحليل سورة الحجرات

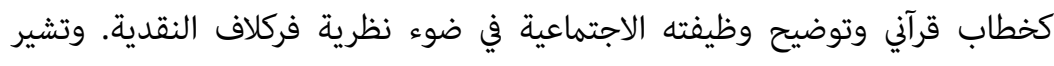
نتائج الدراسة إلى أن خطاب سورة الحجرات في المحور التربوي ينسجم مع الخطاب الموجود السائد في المجتمع ويحاول شرح نظام القيم الإسلامية.

الكلمات الدليلية: القرآن الكريم، سورة الحجرات، الخطاب، فركلاف، التحليل النقدي، السردانية العربية. 
أولاًا) المقدمة

القرآن الكريم هو آخر كتاب سماوي تم تنزيله لهداية جميع البشر وهو كتاب كامل لا يتناول البعد الفردي للبشر فحسب، بل يتطرق إلى الأبعاد الاجتماعية فيعتبر برنامجا شاملا يتحتم على الناس التفكر في آياته على قدراتهم العلمية وإذا كانوا يواجهون صعوبة في فهمها وتفسيرها فعليهم الرجوع إلى المصادر التفسيرية.

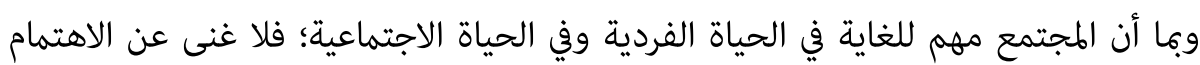

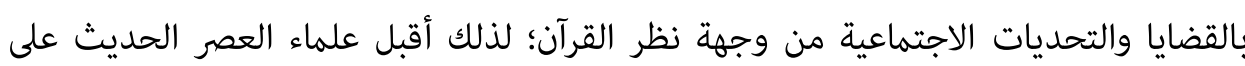

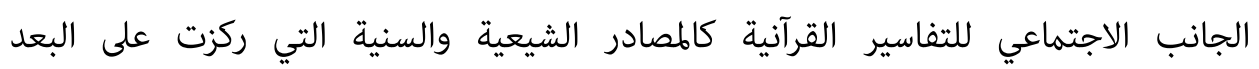
الاجتماعي للآيات، منها تفسير الميزان ومن وحى القرآن والكاشف وفي ضوءالقرآن، والمنار وفي ظلال القرآن، والتحرير والتنوير، وتفسير المراغي ووالتفسير المنير من تفاسير أهل السنة. ومع ذلك، فقد أجريت دراسات مختلفة في شأن تحليل بنية السور القرآنية لكن مازلنا نحتاج إلى تحليل الدلالات المفهومية للقرآن في سياق كامل مثل سورة الحجرات كخطاب ووظيفة التفسير الاجتماعي كمشكلة اجتماعية لفهم البنية التحية لمعاني آياتها. أهداف البحث وأسئلته

يسعى هذا البحث إلى تقديم فوذج لتحليل سورة الحجرات مستلهما من طريقة التحليل النقدي لنورمن فركلاف وتششيا مع أهداف القرآن لاكتشاف الخطابات السائدة وطريقة إنتاجها في مستوياتها العميقة ووظيفتها الاجتماعية؛ لذلك، فإن أهم الأسئلة التي يسعى البحث في الإجابة عنها هي: - إنوي:

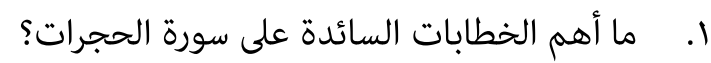
r. ما أبرز السمات الدلالية للسرد القرآني في سورة الحجرات وفق نظرية فركلاف؟

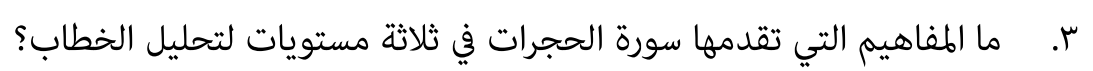
فرضيات البحث ا. يبدو أنّ أهم الخطابات البارزة في هذه السورة هي الخطابات الاجتماعية والتعليمية. 
r. يبدو أن للكلمات في سورة الحجرات علاقات دلالية خاصة وإيديولوجية عالية وقيم علائقية.

r. يبدو أن هذه السورة تنتقل إلينا مفاهيم مهمة مثل السخرية والتوبيخ والإهانة والألقاب المهينة ومراقبة الشؤون الشخصية للمسلمين والقذف وإلخ.

r.إشكالية البحث

الخطاب مفهوم يستخدمه كل من المنظرين والمحلين الاجتماعيين واللغويين. فبالنسبة لرأي فركلاف، الخطاب يعني استخدام اللغة كلامًا أو خطا، وكذلك أنشطة الإشارة الأخرى مثل الصور المرئية (الصور ومقاطع الفيديو) والاتصال غير اللفظي (مثل الإيماءات)”؛ وهذا ما نراه في اللغويات التقليدية ويدعى العمل، والكلام، أو استخدام اللغة. حاول القرآن الكريم مستخدما الكلمات والجمل في سور مختلفة، إنتاج أو تمثيل تصورات ومفاهيم ذات هيكل اجتماعي ومفاهيمي في مجال المجتمع المعاصر والثقافة في مجتمعات لاحقة. فإحدى هذه السور هي سورة الحجرات. سورة الحجرات هي سورة مدنية تعبر عامة عن الواجبات الدينية والاجتماعية للمؤمنين وتتضمن البديهيات نحو: واجب المؤمنين تجاه رسول الله وعدم ارتكاب معصية الله وعدم المخالفة مع الأنبياء في التعبير عن الأحكام الدينية، والواجبات الاجتماعية للمؤمنين ضد بعضهم البعض، والسلام بين المؤمنين ولزوم التجنب عن السخرية والإهانة، وواجب المسلمين تجاه دين الله، واحترام التقوى أفضل من التمييز العنصري، وإلخ. وعلى الرغم من أن هذه السورة تحتوي علىی) آية قصيرة، إلا أنها غنية بالسيميائيات والجماليات الرائعة. ففي الواقع، تروي هذه السورة في لمة واحدة أهم قضايا الحياة البشرية وتحدد نظام القيم الإسلامية للبشر. فنجد الضرورة الكافية لنقد هذه السورة من وجهة نظر

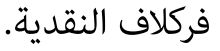

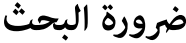

إن الوظائف والنتائج المستهدفة لسورة الحجرات والأثر الهائل الذي خلفه هذا النقاش على الثى تفسير القرآن وعلاقته بالعلوم القرآنية أدت إلى إجراء منهج عام لهذا الموضوع القرآني. فمقاربة الخطاب القرآني من الموضوعات التي تم تكثيفها في الآونة الأخيرة وفي ظل الخطاب والفحص 
الشكلي للسور. برز الاهتمام بالخطاب القرآني أكثر بروزا وجذب انتباه المتحمسين به بالإضافة إلى ذلك، فإن الاهتمام بسياق الجمل والآيات يزيل الكثير من أوجه الغموض التفسيرية ويثري فهمنا

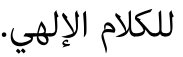
خلفية البحث

فيما يتعلق بالبحوث المعنية بالتحليل النقدي في الخطاب القرآني لسورة الحجرات لم نجد بحثا يهتم بهذا الموضوع ويناقش هذه السورة من وجهة نظر فركلاف النقدية. فقط بالنسبة إلى الأبحاث المتعلقة بسورة الحجرات وجدنا بعض البحوث ونناقشها باختصار: كرمي وآخرون (rوسا) في دراستهم تحت عنوان "تقييم فعالية التعاليم الاجتماعية والأخلاقية لسورة الحجرات على مهارات الاتصال لطلاب السنة الأولى الثانوية في المنطقة الثانية

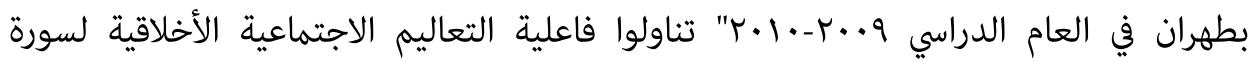
الحجرات في مهارات التواصل الطلابي في إحدى مناطق طهران. الباحثة ديالمه (rوسا) في دراسة معنونة بـ"العقلانية في الهندسة المعرفية لتفسير سورة الحجرات"، أشارت إلى أن الهندسة المعرفية لسورة الحجرات تنطوي على الممارسات الدينية

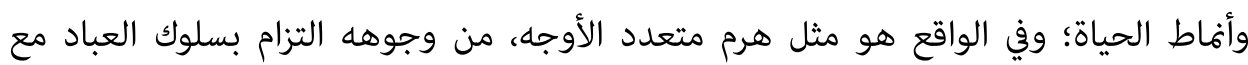
المعبود وتناول أدب أصحاب الرسول(ص)معه و تناول أدب المؤمنين بعضهم بالبعض. ثانياً) الإطار النظري للبحث الخطاب النقدي الخطاب هو معادل للكلمة الفرنسية "ديسكورس"، وهو مصطلح لغوي دخل بسرعة في العلوم الإنسانية وبدأ يستخدم على نطاق واسع. استخدم زيليج هاريس لأول مرة هذا المصطلح (بهرامبور ، (Y.،Vq). يستخدم جي كادين الخطاب للإثارة إلى خطاب علمي ومفصل للغاية من الكلام أو الكتابة الفلسفية والأدبية، وهلم جرا (يارمحمدي، سيسا، Vإ). كما حدد العلماء الخطاب على أنه جماع لفظي، والعلاقة المتبادلة بين المتحدث والمستمع، وإعادة صوت في قلب

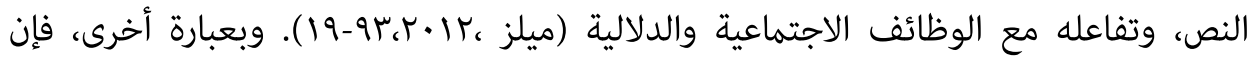




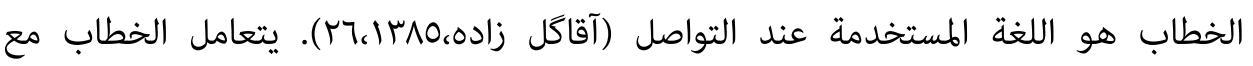

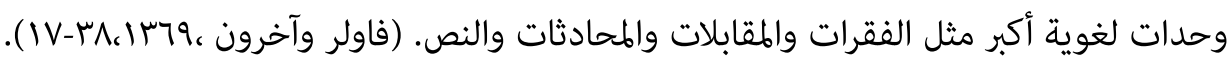
تحليل الخطاب النقدي هو أحدث نهج لتحليل الخطاب."هذا النهج يتأثر فلسفياً بوجهات نظر ميشال فوكو وفرويد وماركس -وهو يعتزم ربط موقف الدلالات للعبارات بعلاقة اللغة بالقضايا الاجتماعية ونقلها إلى النقطة التي يعتبر فيها اللغوي نفسه عنصراً مسؤولاً في الشؤون

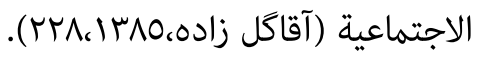

يسعى التحليل النقدي للخطاب أن يمر على المستوى الوصفي للنص و أن يقف إلى إلى الجانب التحليلي له ومن ثم يحاول الجمع بين عوامل متعددة كالإيديولوجيا والسلطة والتاريخ و بين اللغة فيأخذ في الاعتبار الواقع اللغوي الأكثر شمولية لتفسير النص. من وجهة نظر حفني، الخطاب هو "(نقد للأعمال الأدبية والفنية، للتعبير عن جمالها، والرسوم التوضيحية والأساليب، والقدرة على التأثير على القارئ وإثارة مشاعره)(حفنى، 199 ، דז؟ صمود، + . T، 10). تحليل الخطاب هو وسيلة لكشف الحقيقة في النص وكل نص يحاول كشف الحقائق التي تدور في ذهن المؤلف واتجاهاته فنورمان فركلاف هو أحد الشخصيات الرائدة في تحليل الخطاب النقدي. ففي رأيه، تحليل الخطاب النقدي هو وسيلة تستخدم جنبا إلى جنب مع وسائل أخرى لدراسة التغيير الاجتماعي والثقافي.يفحص فركلاف تحليل الخطاب على ثلاثة مستويات: الوصف والتفسير والشرح(فركلاف، OVVIII). هو يؤمن أن النص في المقام الأول لديه عمومية التي يعتمد عليها ، يوجد داخل النص مجموعة من العناصر ، بالإضافة إلى كونها مرتبطة ببعضها

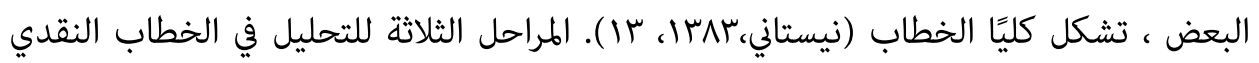
لـفركلاف هي: I. الوصف

في هذه المرحلة، يتم تحليل النص بشكل منفصل عن النصوص والسياقات الاجتماعية الأخرى. ويكن اعتبار مجموعة الميزات الرسمية الموجودة في النص كاختيارات محددة بين خيارات المفردات وقواعد اللغة المتوفرة التي يستخدمها النص. هذا التحليل هو تحليل مجرد 
للنص. يفحص فركلاف التحليل التجريدي للنص على مستوى المفردات والهياكل النحوية والبنية النصية (فركلاف، IVV9، IVI - IVI). على سبيل المثال، في هذه المرحلة نجيب عن الأسئلة التالية

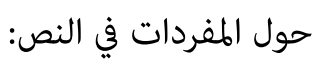
- هل الكلمات لها قيمة تجريبية؟ أي نوع من العلاقات الدلالية الايديولوجية نشاهد بين الكلمات؟ -ما الكلمات التي لها قيمة علائقية؟ هل هناك كلمات يمكن تفسيرها جيدًا؟ هل هناك كلمات رسمية أو محاورية؟ - وما وظيفة الاستعارات في الكلمات؟ وما القيم التجريبية الموجودة في المصطلحات النحوية والشكلية؟ هل الجمل معروفة أو غير معروفة؟ هل الجمل إيجابية أم سلبية؟ (المصدر نفسه). r-مرحلة التفسير في مرحلة التفسير ، يتم إنتاج النصوص وتفسيرها استنادًا إلى فرضيات تقدر الخصائص النصية. إن التفسيرات هي مزيجة من محتوى النص وعقلية المفسر التي يتم استخدامها في تفسير النص(فركلاف، السياقات النصية تتزامن مع المعرفة السابقة مثل النظام الاجتماعي والتفاعل التاريخي .ففي

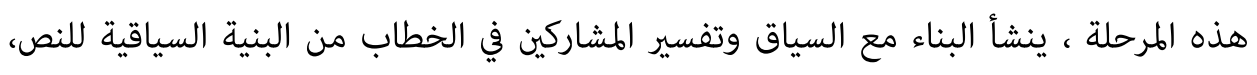

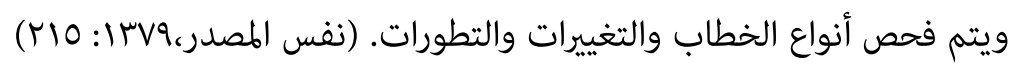

\section{r. مرحلة التوضيح}

في هذه المرحلة، يحلل الباحث النص كجزء من عملية النضال الاجتماعي داخل علاقات

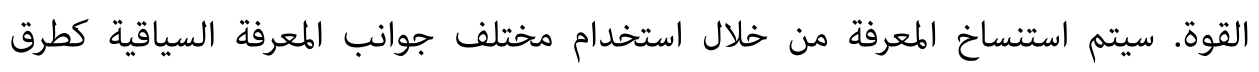
تفسيرية لإنتاج النصوص وتفسيرها. فيتم استنساخ المراحل المختلفة للترابط بين التفسير

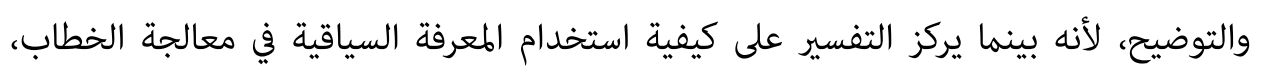
فلابد من شرح التفسير الأساسي وتغيير المعرفة السياقية واستنساخها في تدفق المواقف ئفي الاستطرادية ما يجب مراعاته في مرحلة التوضيح. 
نزلت هذه السورة في المدينة المنورة ولها ثمانية عشرةآية وتسمى "الحجرات أو سورة" الآداب والأخلاق ". وهناك رأي آخر أنه جاءت تسمية هذه السورة بالحجرات لأنها نزلت حول حجرات النبي (صلى الله عليه وآله سلم) التي كانت بسيطة للغاية (قرائتى، • ^זו, ب: سا). وتعدّ سورة الحجرات من سور القرآن الفريدة من حيث التعبير عن القضايا الاجتماعية و التركيز على معايير المجتمع النموذجي والإسلامي نظرا لا تنطوي السورة من مضامين اجتماعية كثيرة. يمكن أن تكون القواعد الاجتماعية الموضحة في هذه السورة ميثاقًا لحل المشكلات الشخصية بالإضافة إلى فوذج لمنع الحالات الشاذة الاجتماعية.

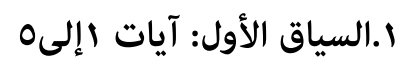

هذه الآيات تريد إنشاء مجتمع يمثل فيه النبيُ حاكم الحكومة، وأول شخص في المجتمع ترتيبا وعلى الناس اتباعه فلابد لهم ألا يجهروا صوتهم على صوت النبي، وهذا يدل على ملى استعدادهم لمتابعة النبي، وإلا لا يصلون إلى التوفيق في أعمالهم.

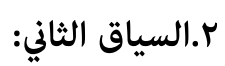

في السياق الثاني للسورة نجد أنه كان ممنوعًا التجاوزُ عن أوامر النبي بناء ما ورد في هذه النها الآيات ومن أسبابه، تجاهل المكانة العالية لرسول الله من قبل أمته وجعله شخصا عاديا كسائر الأفراد في مجتمعه. في المجتمع الذي يعتبرون أنفسهم على مستوى النبي خلاف واقع الأمر في الحياة الاجتماعية، فالنتيجة ليست إلا ولاية الأشرار و غير ذوي صلاح؛ أي أن الأشرار في هذا المجتمع يأخذون النبرة ويحرضون المؤمنين على بعضهم البعض. فهذا الأمر أيضا يؤدي إلى زيادة إنها

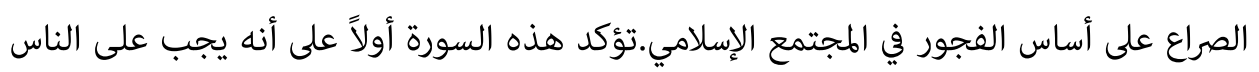
متابعة النبي و أوامره. إن الخطوة الثانية في هذه السورة هي إزالة النزاعات و من أجلها تناقش تآخي المؤمنين وتشجيع الأخوة بغية إحباط الصراعات.

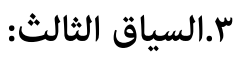

والسياق الثالث للآيات يدل على أن المؤمن عليه التحدث مع النبي برفق ولين. وعليه ألا يتحدث بكبر وأنانية معه، والمؤمن لا يتخطى عن نبيه. 


\section{رابعاً) تحليل مستوى الوصف}

يكنن أن تشمل المناقشات التي يتم فحصها في مستوى الوصف على القيم التجريبية والعلاقات الدلالية للمصطلحات الايديولوجية والقيم الترابطية والتعبيرات الرسمية أو التفاعلية والاستعارات والنحو وجمل معروفة وغير معروفة، وجمل إيجابية و سلبية، ومقالات إخبارية، وأسئلة، واستخدام ضمائر نحن وأنتم، وجمل بسيطة ومركبة ، وإنشاءات نصية.

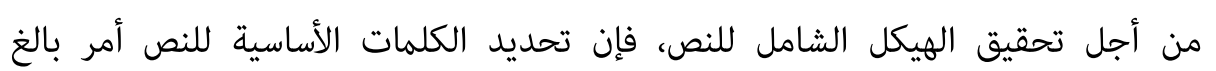
الأهمية.و من امللاحظ أنه بعد دراسة المفردات في سورة الحجرات، يبدو أنه من الممكن تحديد بعض الكلمات الرئيسة فيها مثل التقوى، والفسق، والجهل، والعلم، والعدل، والظن، والإيمان، والكفر التي هي في الواقع الكلمات الرئيسة للسورة ولديها قيمة ايديولوجية. تمثل سورة حجرات خطابًا اجتماعيًا بين القائد و رعيته، وبعبارة أخرى، تسعى هذه السورة إلى تصوير علاقة ايديولوجية وقيمة بين جميع مستويات لغوية، سواء أكانت مفردات أو جمل. إذن الخطاب اللغوي لهذه السورة يتميز باستخدام مفردات محددة في موضوعات العدل و المعرفة والايمان والكفر وقضايا أخلاقية وتعليمية. فقال الله تعالى: ”يا أيها الذين آمنوا لا تقدموا...) و "يا أيها الذين آمنوا لا ترفعوا أصواتكم فوق صوتيه صوت نبى هذه الأوامر السلبية تدل على وجود نوع من العلاقة بين الرئيس و المرئوس؛ بالطبع ، هذه العلاقة لا تستمر إلى نهاية السورة ، وتستمر في تصوير علاقة إيديولوجية وقيمة من أجل بناء مجتمع مثالي. مجتمع يفوح برائحة الأخلاق و التصرفات الأخلاقية:إن الذين ينادونك من وراء

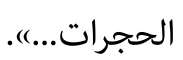

إن وجود أفعال النهي"لا ترفعوا أصواتكم،ولاتجهروا له) التي توجه للمؤمنين، يدل على آلى

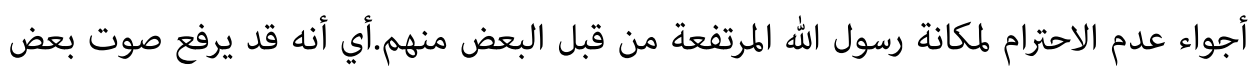

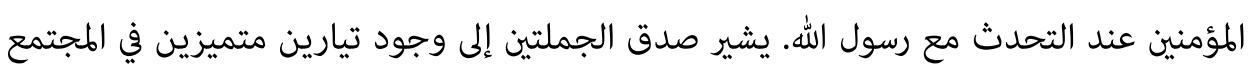
الديني فيما يتعلق بثقافة الارتباط بالنبي(صلى الله عليه وآله وسلم).و من الممكن توضيح مختصر عن المجموعتين للناس هنا: 
المجموعة الأولى هم الذين يرغبون بخفض الصوت أمام النبي صلى الله عليه وآله سلم الذي

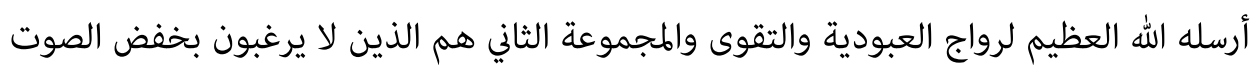

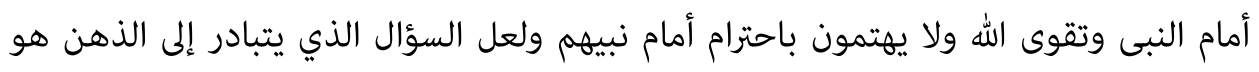
كاذا قد أتى فعل النهى أولاً ومن ثم فعل الأمر؛ لأن هناك مساحة للنهى في أجواء المجتمع في سورة الحجرات وأصبحت عادة النبي بين الناس ورسول الله والناس يتم تجاوزهم بسهولة. يشير فعل الطلب" إن جاءكم فاسق بنبأ......" إلى أن المؤمنين، مع خبر من قبل غير عادل،

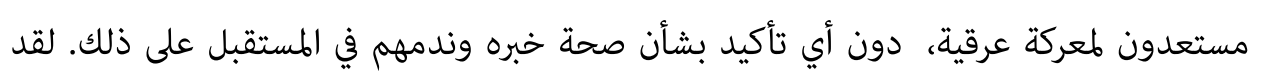
تم التصديق على ذلك من قبل المجموعتين. أشار تواجد رسول الله بين المؤمنين في سياق الشرطية السابقة إلى أن المؤمنين في قرارهم لمحاربة إحدى القبائل على أساس معلومات كاذبة، لا ينتبهون إلى وجود النبي فيما بينهم

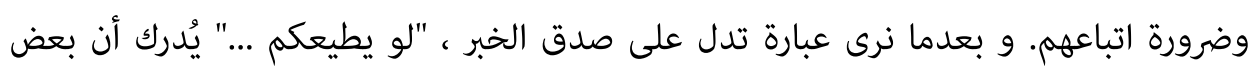

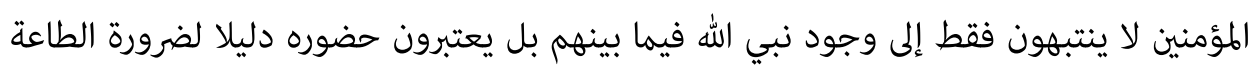
منه ، ولكن بعضهم يتوقعون أن يطيعهم النبي.أي أنهم يتوقعون من الرسول تأييد قرارهم ومرافقتهم في المعركة مع الشعب المذكور. يشير هذه العبارة " إن طائفتان ....." إلى جو التوتر بين مختلف قبائل المؤمنين لدرجة قد يرفضون قبول السلام والغزو. ثم يشير تنبيه المؤمنين إلى السلم العادل (فأصلحوا بينهما بالعدل ...) إلى إمكانية التحيز المتعصب تجاه القبائل دون الالتزام بالعدالة.إن التأكيد على أخوة المؤمنين و واجبهم في الإصلاح بين شقيقيهما (إفا المؤمنون ...) يشير إلى أنه قد يتم إهمال

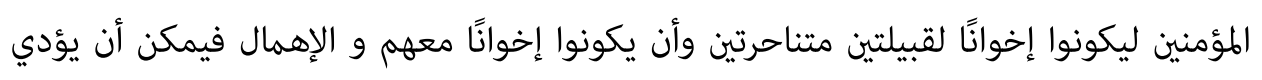
إلى التعصب الشامل الفتاك.

إن فعل "اتقوا الله" في ضوء أمر الإصلاح يشير إلى أن هناك احتمالا ضئيلا للتقوى في هذا

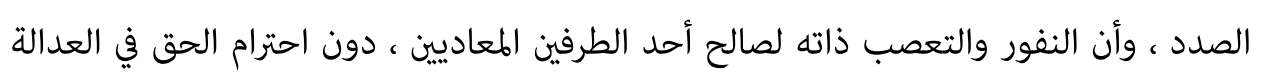
ودون الاهتمام بالأخوة هو صراع مع الجانبين. 
وإن العبارة "لايسخر ..." (لاتلمزوا ..) (لا تنابزوا.....) موجهة إلى المؤمنين ، مما يعني مساحة للسخرية لبعضهم بعضا، ولومة بعضهم البعض، و وضع الأسماء والألقاب المشعرة بالفسق عن

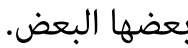

يدل وجود الجملة الإخبارية مثل (و من مل يتب.....) على المساحة الخطابية في الفقرة

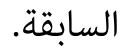

و تشير صيغة الأمر (اجتنبوا....)وأفعال النهي (لا تجسسوا ..) و(و لا يغتب...) الموجهة إلى المؤمنين، إلى أجواء من الشك تجاه بعضهم البعض، والبحث السلبي عن بعضهم البعض من أجل فهم الأخطاء و سوء الفهم بين بعض المؤمنين. ثم نرى أن التاكيد على خلق البشر من الوالدين والتعبير عن فلسفة جعل الناس و القبائل شعوبا (جعلناكم شعوبا ..)يدلان على تعدد الشعب والقبائل في مجتمع المؤمنين وعدم قبول حقيقة المساواة بين الفروع والقبائل الإنسانية من حيث أصل جميع القبائل من جانب بعض المؤمنين وعدم الاهتمام بأهمية هذا الأمر. وإن الجملة التأكيدة مع إن (إن أكرمكم عند الله أتقاكم...) وسياقها يدلان على أن بعض المومنين يعتبرون الأشياء الأخرى مثل العرقية و النسب مقياسا للتفوق والكرامة دون أن يعتبروا التقوى مقياسا لهما. إن صدق الجملة الخبرية (قالت الأعرابُ...) يدل على سياق دعوى الإيمان من قبل فريق

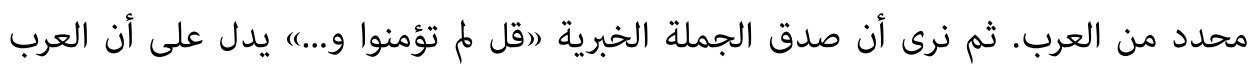
الذين يدعون إلى الإيمان، مل يؤمنوا فعلاً بل استسلموا وم يدخل الإيمان قلوبهم بعد.ثم تدل عبارة ( إن تطيعوا الله و رسوله...) موجهة إلى العرب على أنهم اكتفوا بالدعوى فقط ومل يطيعوا الله و رسوله. حصر تعريف المومنين مع خصائص كالإيمان بالله و رسوله و عدم وجود شك في قلوبهم بعد الإيمان و الجهاد فى سبيل الله بالهال و النفس ( إفا المومنون....) و الجملة الخبرية (اولئك هم الصادقون ) فى هذا السياق، تدل ضمنيا على أن ادعاء بعض العرب بأن هذه الخصائق ليست صادقة بينهم و هم كانوا متشككين بعد الإيمان والجهاد فليسوا مجاهدين في سبيل الله بالهال والنفس صادقين ، وبالتالي فإن المطالبة بإيمانهم ليست صادقة. 
وتدل المساءلة بالتوبيخ ( قل أتعلمون الله بدينكم...) موجهة للأعراب في هذا السياق، على أنهم ليسوا مطالبين بالكذب ولكن يريدون أن يعلموا الله بحكم مسارهم العملى و دفاعهم. بعبارة أخرى ادعاءهم ومسار السلوك عندهم يشيران إلي أن حقيقة الإيمان هى التي قمسكوا بها ظاهريا. وصدق الجملة الخبرية( يمنون عليك أن أسلموا....) يشير إلي أن العرب الملدعين للإيمان، يمنون على رسول الله من أجل إيمانهم. يدل تناسب الأخبار من علم الله تعالى لغيب السماوات و الارض ووعيه بأعمال المخاطبين (الأعراب) ( إن الله يعلم .....) على الطبيعة المجوفة للأعراب على الآخرين، يعنى قبل هذا الكلام وهذه السورة مل يكن المؤمنون مدركين لطبيعة هولاء الأعراب، وكشف الله عنها.

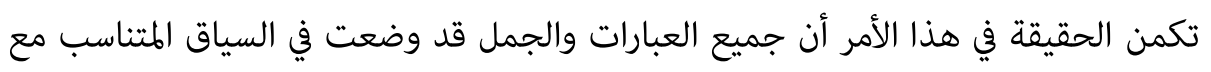
معانيها لتوصيل رسالتها بشكل صحيح. خامسا) التحليل في مستوى التفسير التفسير هو مزيج من محتوى النص وعقلانية المفسر. أما عقلانية المفسر فهي المعرفة السياقية التي يستخدمها في تفسير النص وبالنسبة للمفسر ، فإن خصائص الظاهرية للنص هي مي مئري في الواقع الفكرة التي تنشط عناصر المعرفة الأساسية لعقله.وسيكون نتاج العلاقة الجدلية لهذه

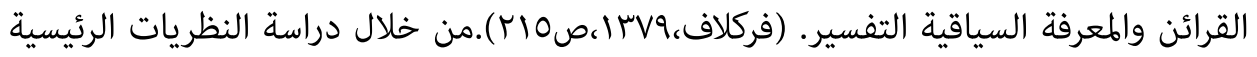
للنص وكيفية إلحاقها من ناحية ودراسة الموضوعات الرئيسية في النص من ناحية أخرى ، تم

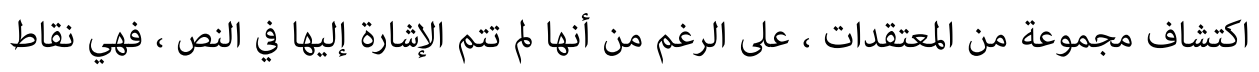
الاعتماد على النص. يتم الإجابة على الأسئلة التالية على مستوى التفسير:

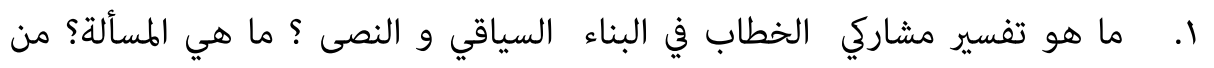
يشارك؟ ما هي العلاقات بينهما وما هو دور اللغة في تقدم القصة؟ r. ما نوع الخطاب الذي سيتم استخدامه ونتيجةً للقواعد والأنظمة والمبادئ التي يتم تطبيقها على النظام الصوتي والنحو وترابط الجملة والهفردات والأنظمة الدلالية مع التطبيق

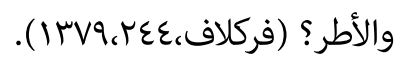


تصور سورة الحجرات فضاء يواجه فيها المجتمع الإسلامي اختبارًا إلهيًا من خلال أفعال الناس. من ناحية أخرى، هذه السورة هي إحدى السبل الحاسمة لتقديم حل للمجتمع الإسلامي المتنامي. التفكير والتأمل في العناصر المعرفية لكل سورة واكتشاف علاقتها واتساقها الداخلي وفقًا لبدأ الغائية والغرض ،إنه يمثل بنية شاملة ومنتظمة في السور القرآنية التي سوف يكشف مخططها عن الهندسة المعرفية لكل سورة حتى يتسنى توضيح موقف كل عنصر معرفي في مجموعة النظام الفكري ، وفي النهاية النظام المعرفي للقرآن الكريم (دياله، بوسا، 00).ففي تفسير سورة الحجرات، إنها قصة ذات طابع اجتماعي-سياسي ، وهي نوع من المظاهر الاجتماعية والتربوية في المجتمع ، وشخصية النبي في هذه السورة هي القيادة التي يجب على إنى شعب المجتمع أن يطيعها. لسورة الحجرات وحدة الموضوع والغرض ، وهو الحل للأزمة التي نشأت في المجتمع الإسلامي في عهد النبي لتوضيح أجواء الوحي للسورة ، ومراقبة نهو المجتمع الإسلامي في وقت الوحي من القرآن (ومازالت موجودة أيضا). والتعبير عن الفحوصات الإلهية والأزمات بشكل

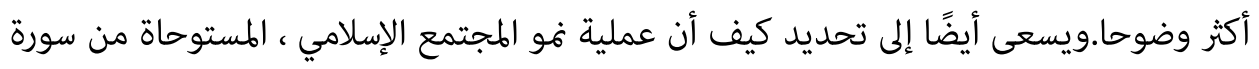
الحجرات ، هي وسيلة لمعالجة الأزمات التي قد تواجهها المجتمعات الحالية.إنها تخيم على إلى أزمة تدمير موقع النبي في المجتمع الإسلامي.لذلك ومن خلال أوامره، أولاً ، طريقة تدمير شخصية النبي محجوبة ويستمر في مواجهة المجالات التي أدت إلى استخدام المنافقين لها في خلق هذه الأزمة.إن هذه السورة تتغلب على أزمات التفوق الناجمة عن الادعاءات الخاطئة بالإيمان ،وإن نشاط هذه الحركة قد عرّض للخطر علاقة الطاعة والولاية بين المؤمنين والنبي، وبالتالي فقد تضررت أخوة مختلف الجماعات المجتمعية الدينية. وفي مواجهة هذه الأزمة، ينظم أولاً العلاقة بين الطاعة والولاية ، والتي تسعى في ضوءها إلى إصلاح العلاقة الأخوية ، وتكشف في النهاية عن التدفق العربي المحايد وتتوج بنمو الأمة الإسلامية.وفي تعبيره عن أمراض هذه العملية، ينص القرآن الكريم على أن وضع النبي كحاكم إسلامي في البداية سيضعف وأن الفاسدين سيتصفحون المجتمع ويخلقون الشكوك والخلاف بين 
تتناول هذه السورة أولاً ضرورة إصلاح العلاقة بين المؤمنين والحاكم الإسلامي ويقترح ألا يتقدم أحد على النبي وأن يطيعه الجميع وفي الخطوة الثانية ، ضع في اعتبارك الأزمة الأكثر عمقًا والسعي لإصلاح الثقافة العامة للمجتمع. ففي هذه الأثناء، يجادل أولاً بإيجابية وينظر إلى إلى إخوة المؤمنين بعضهم البعض ، ثم يسعى لمواجهة ثقافة التنابز والشك و أخيرًا ، يتساءل أساسًا عن السبب الجذري للتنابز و التجسس والخطوة الثالثة هي إصلاح علاقة المؤمن بالله. أول شيء فعله هو معارضة من المسلمين لإيمانهم.يجب أن يستند الإيمان الحقيقي إلى إيمان القلب إلب

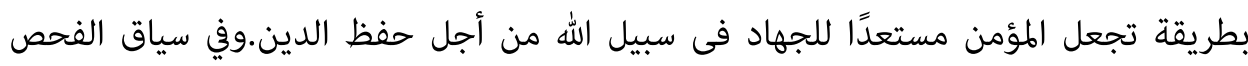
الإلهي للقرآن الكريم ، تسعى هذه الأوامر الثلاثة إلى زيادة فهم المجتمع الإسلامي وفضح الوجه

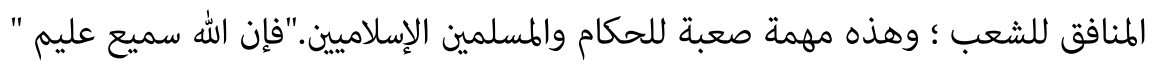
السبب الذى أدى الى إتيان صفة السمع لله تعالى هو: أي أن هناك كلمات وأحاديث مبينة

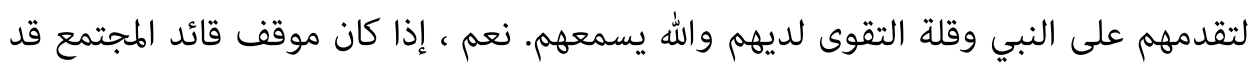
تعرض للخطر وتم محاذاة العديد من الأصوات.فنتيجة لذلك ، لا يمكن التعرف على أوامره

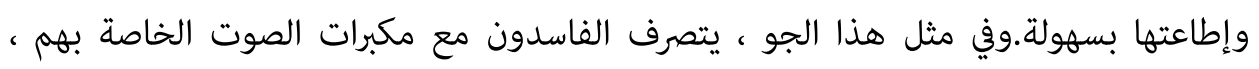
والتي تعد أيضًا مستوى مجتمع النبي والقائد ، وتحث المؤمنين على التناضل مع أشخاص آخرين ،والقرآن يحذر المؤمنين من عدم الانخراط مع أمة من الجهل ثم نأسف لاتباع كلمة المفسد. "لو يطيعكم في كثير من الأمر لعنتم" ينص على أن الناس قد ضغطوا على النبي لجعلهم يطيعونه ،

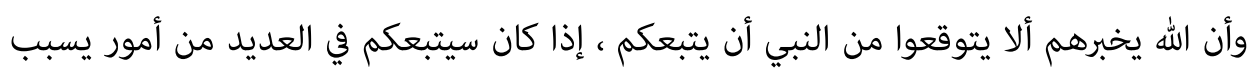
الإزعاج والإرهاق.

يتحدث القرآن الكريم بألا يتبع الناسُ الفاسق و يوصى بإتباع رسول الله ويخاطبهم بأنك لا

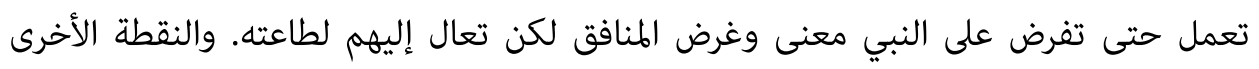
هي أن الجمل السابقة كانت مخاطبة للمؤمنين ،لكن هذه الجملة غائبة، وهذا الاختلاف في التفسير، على ما يبدو لإظهار أن هذه الجملة ليست خاصة بأصحاب النبي، بدلا من ذلك ، إنه قانون عالمي بأن كل شخص يحافظ على طبيعته في كل عصر وزمن هو شخص الخلاص والتوجيه.والتقوى المبين في هذه الآية هو التقوى الثاني في هذه السورة ، الآية الأولى هي الولاية والآية الثانية، الإخاء تحت ظل الوصاية.إنه يسعى لإطاعة رسول الله أن هذه الأخوة هي التي 
خلقها الإيمان بالله لا يتسامح مع الصراع بين المسلمين لأنه يسبب الضعف وفقدان الشخصية

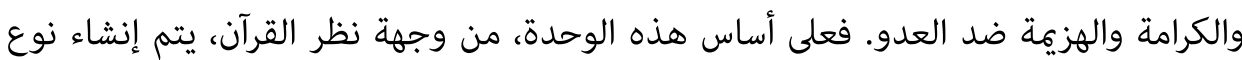

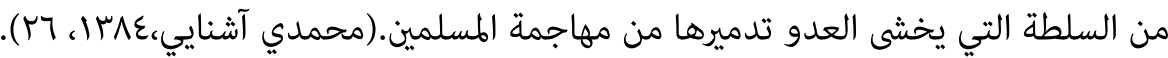
تتطرق آية لا من سورة الحجرات بالنسبة للآية السابقة متعمقة، إلى أحد أسباب الصراع وهو تقدم الأحزاب عن النبى ، فالأرض قد تكون غيرمطلوبة لتعامل بعض الاشخاص للبعض، علاقة هذه الأحزاب بالنسبة بعضهم البعض كالقارورة التى يمكن بسبب عدم العناية للأوامر حاكم الجامعة الإسلامية ينفجر، بعبارة أخرى حينما يزول الأدب الشائع بين المومنين و تكون الظروف السائدة بين المسلمين بالصورة التى ينادي المومنون بعضهم البعض دون مراعاة الأدب مما أدى إلى تسرب هذا السلوك للحاكم الاسلامي و يعتقد الناس أن الحاكم الإسلامي أيضا يكون مثلنا فلماذا نتبعه؟ وهذا الموضوع نفس الأزمة التى يشار إليها فى أول السورة. وتبعا هذه السورةتكون بمثابة عرق جميع الأزمات و يراد أن يحدد عرق جميع الأزمات كما قد تطفأ أزمة الحرائق الأولية، السبب الذى تخاطب الآية المومنين بالعبارة "يا أيها الناس) هو أنها يريد أن يعبر عن كلام لا يخص المؤمنين فقط، وجدير بالذكر أن (أتفاهم) فى هذه السورة هم الذين يخطون وراء النبى والذين يطيعون الرسول ويراعون الأخوة فى اطار الوصاية.

\section{سادساً) مرحلة التوضيح} الغرض الأصلي لهذه المرحلة في تحليل الخطاب النقدى هو توضيح دور المرحلتين السابقتين يعنى الوصف و التفسير، ويعتمد التوضيح على العلاقة بين التفاعل والسياق الاجتماعي. في الواقع، يمكن أن نشير إلى المحددات الاجتماعية لعمليات الإنتاج والتفسير والآثار الاجتماعية.

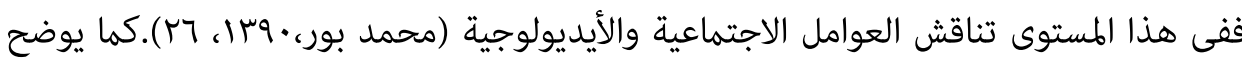
كيف يمكن أن يكون للخطابات تأثير على الهياكل الاجتماعية السياسية التي تؤدي إلى الحفاظ على تلك الهياكل أو تغييرها.

في هذه المرحلة، قت مناقشة سورة الحجرات على المستويات المؤسسية والاجتماعية كعنصر في نظام المجتمع الإسلامي. في هذه المرحلة، يكن للمرء أن ينظر إلى موقف السورة من حيث تواجد القضايا الاجتماعية والثقافية من التعليق أو التفسير إلى المرحلة التوضيحية. وتجدر 
الإثارة إلى أنه باستخدام المعرفة الأساسية كوسيلة تفسيرية في إنتاج النص وتفسيره، ستتم إعادة إنتاج هذه المعرفة.

إن الاستنساخ يربط المراحل المختلفة للتفسير والشرح ويركز التفسير على كيفية الاستفادة من المعرفة الأساسية في معالجة الخطاب كما يتناول توضيح الأسس الاجتماعية والتغييرات في المعرفة الأساسية للأمور وكذلك استنساخها أثناء العمل الاستطرادي. والغرض من مرحلة التوضيح

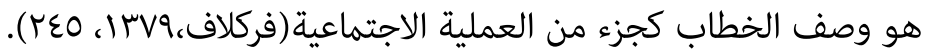
هناك أسئلة حول مستوى توضيح العوامل الاجتماعية والإيديولوجيات وتأثيراتها على المجتمع وهي: ما نوع علاقات القوة على مختلف المستويات المؤسسية والاجتماعية والظروف التي تكون فعالة في تشكيل هذا الخطاب؟ ثم أي عناصر من المعرفة الأساسية المستخدمة لها طابع أيديولوجي؟ ما هو موقف هذا الخطاب من النضالات على مختلف المستويات المؤسسية والاجتماعية والظروف؟ هل هذه النزاعات عامة أم سرية؟ هل الخطاب متعلق بالمعرفة الأساسية المعيارية أو الشاذة؟ هل يجهد هذا الخطاب للحفاظ على علاقات القوة القائمة أو العمل على تغييرها؟ فوفقًا ما حدث على مستوى الوصف والتفسير، يتم شرح أجواء كلمات السورة. فنرى أنه يتضح من محتوى الوصف، والتوضيح أن أحد أغراض السورة هو النهى من التنابز للتفوق القبلي. فبالطبع، يكنن للمرء أن يتخيل مساحة فيه: أول شيء أنهى منه هو الاستهزاء من بعضنا البعض، والتي تأتي أولاً مع عبارة ".لا يسخر قوم من قوم. إذا كانت كلمة "قوم" في هذه الآية تعني بكعناه المتبادر، الذي يكمل صلاحيته النسبية للمطالبة؛ ووفقا لرأي بعض المفسرين، كلمة "قوم" في هذه الجملة تتناقض مع كلمة "نساء" في الجملة (لا نساء من نساء..) تعني الرجال، ثم

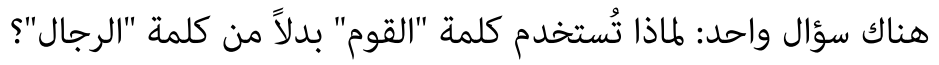
قد يهدف الله تعالى إلى تحقيق غرضين، لقد منع كل من الرجال والنساء من السخرية من بعضهم البعض ومنع الأقوام أيضا من السخرية فيما بينهم. ففي هذه الحالة، مرة أخرى، ستكون لهذه العبارة أهمية المطالبة. ومع ذلك، من نافلة القول إن إثبات الظروف القبلية لا تنفي استخدام هذه الثقافة بين المؤمنين. فأجواء سورة الحجرات هذه هي أزمة التفوق العربي التي 
تهدد علاقة المومنين مع النبى وبعضهم البعض. يمكن توضيح هذه المساحة في العديد من الحالات مثل:

عدم العناية لمكانة قيادة رسول الله في التواصل مع بعض المسلمين الذين يولون قدراً ضئيلاً من التقوى لضرورة الإطاعة من النبي في صنع القرار وهذا أدى إلى نزاع المسملين بعضهم البعض. الصراع بين بعض عشائر المؤمنين والتحيز المتعصب لبعض العشائر تجاه جانب واحد هو نتيجة عدم وجود الأخوة والطساواة بسبب ما نرى من سوء السلوك الاجتماعي مثل السخرية والتحقير والتي بدورها هي وظيفة من الحيز المذكور في الفقرة الأولى. يتم سرد المساحة المذكورة في الفقرتين الأوليتين من قبل مجموعة من العرب الذين يدعون بايمانهم الكاذب ويمنون على النبي بإيمانهم. فأولئك الذين يفتخرون بالاستسلام ويمنحون لأنفسهم الحق في اتخاذ القرار والقيادة طوعا أو كرها، ويستخدمون هذا الحق لتخريب الناس والقبائل الأخرى للمسلمين على أساس الأسبقية القبليةو لا التقوى. ففي الواقع، جميع المكونات التي تم تضمينها في هذه هرها السورة هو جزء من معجزة القرآن الكريم والاهتمام الكامل من الله بحاجات الإنسان.فالنظر في المكونات الثلاثة العلائقية والإدراكية والهيكلية من شأنه أن يسهل العلاقات الاجتماعية والعلاقات المتماسكة بين الأفراد.

\section{سابعا) النتائج}

نظرا لأن التحليل النقدي للخطاب يُعنى بدراسة اللغة والخطاب و المجتمع، تجلى لنا أن مراعاة السياق تكون شرطا أساسيا في فهم النص أو الخطاب القرآني في هذه السورة؛ حيث يفسر السياق الكثير من العمليات المصاحبة للأداء اللغوي القرآني. إن سورة الحجرات تناقش حواجز التواصل والتعامل في المجتمع مثل السخرية والتوبيخ والإهانة و إطلاق الألقاب المسيئة والتجسس في الشؤون الشخصية للمسلمين واغتتاب بعض البعض. وتحذر المؤمنين من الولوج إلى هذه المسائل و القضايا التي تسبب الحقد و الضغينة بينهم.ومن ناحية أخرى، فإنها تشمل القضايا الأخلاقية والاجتماعية مثل ضبط النفس و التقوى، والمسؤولية عن بعضها البعض، والاهتمام بحقوق الآخرين في العلاقات الشخصية. من حيث الجانب الإرشادي في آيات السورة ،إنه لا يقتصر على زمن نزول السورة، وبالتالي لا يقتصرخطاب السورة على وقت نزوله .ويكن 
اعتبار الخطاب في هذه السورة خطابًا اجتماعيًا تربويًا تم إبرازه من خلال ذكر النبي(ص) كرمز

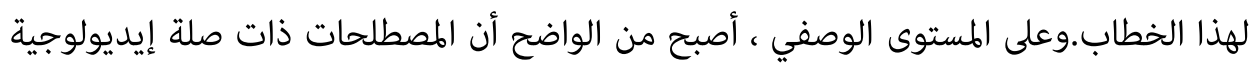
تسعى في ندائها إلى تحقيق هدف التنمية الاجتماعية لزعيم المجتمع.وعلى مستوى التفسير، تبين لنا أيضًا أن السورة تصور الظروف التي يواجها المجتمع الإسلامي اختبارًا إلهيًا من خلال أفعالهم.ومن ناحية أخرى، تعد هذه السورة خطةأساسية لتقديم حل للمجتمع الإسلامي المتنامي ، والسورة في الواقع تصور رمزا لتنمية المجتمع في وقت التراجع وما بعده.وأخيرًا ، يكن القول أن سورة الحجرات، بأعمق مستويات في معانيها، تحدد رمزا إلهيا و تشير إلى أن التنشئة الاجتماعية رهينة قائد المجتمع واتباعه لتحقيق الرخاءضروري وهذا ما يضمن نجاح المجتمع.

\section{المصادر والمراجع \\ القرآن الكريم.}

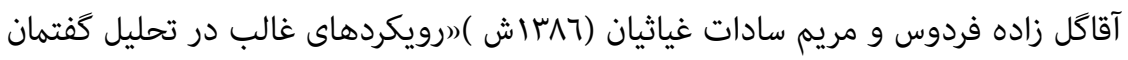

انتقادى)، مجله زبان و زبان شناسى، سال سوم، شماره اول. بهار وتابستان،صصوس-عه آقاكل زاده، فردوس، (0رباش). تحليل كفتمان انتقادى، تهران: انتشارات علمى و فرهنكى.

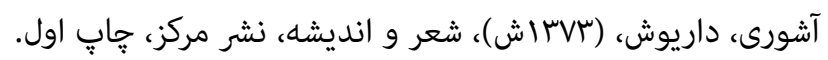

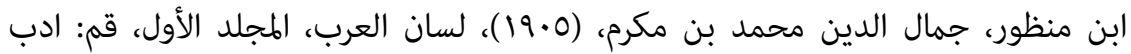

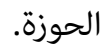

بهرام يور، شعبانعلى، (تواش)، "درآمدى بر تحليل كفتمان)، مجموعه مقالات كفتمان و

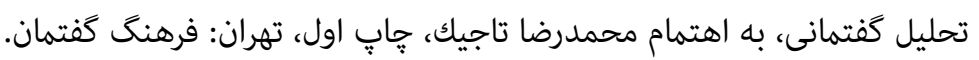

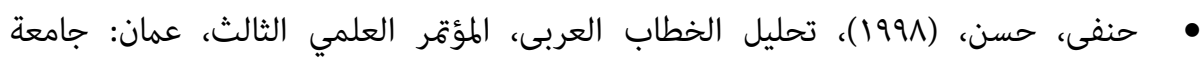
فيلادلفيا. جهانكيرى، جهانكير و بندر ريكى زاده، على، (זوساش)، زبان، قدرت و ايدئولوزى در رويكرد انتقادى نورمن فركلاف، يزوهش سياست نظرى، شماره ى عا، صص r I - OV. 
رستم يور، رقيه و مينا ييغامى، (اوساش)، (اتحليل الخطاب السياسي على المستوى الصرفي في أشعار سميح القاسم (موازنة بين اشعار قبل حرب 199V وبعدها)،، مجلة الجمعية العلمية

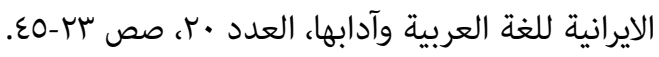
دياله، نيكو، (זوباش)، (خردورزى در هندسه معرفتى تفسير سوره حجرات)، فصلنامه

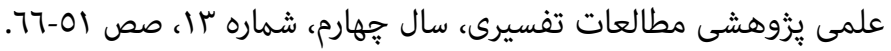

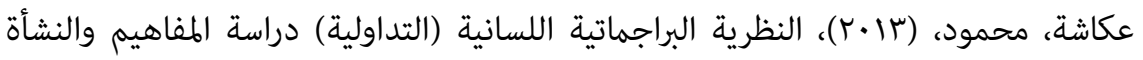
والمبادئ، القاهرة: مكتبة الآداب. عضدانلو، حميد (•^شاش)، كفتمان و جامعه، تهران: نى.

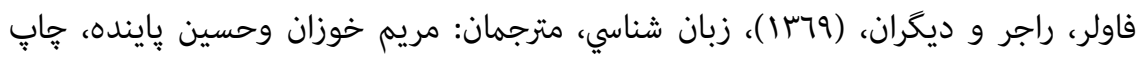

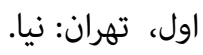
فركلاف، نورمن، (وساش)، تحليل انتقادى كثتمان، مترجمان: فاطمه شايسته يقيران و ديكران، ويراستاران: محمد نبوى و مهران مهاجر، جإٍ اول، تهران: مركز مطالعات و و تحقيقات رسانه ها.

قرائتى، محسن، (•^باش)، تفسير سوره حجرات، تهران: مركز فرهنكى درسهايى از قرآن.

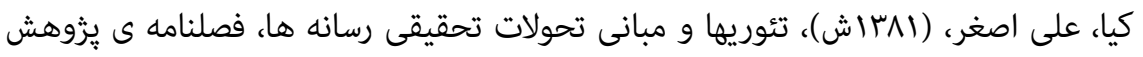
و سنجش، شماره ז"، سال نهم.

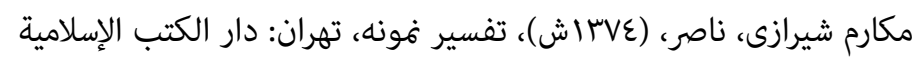

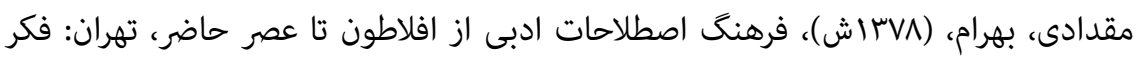
مك دانل، دايان، (•^باش)، مقدمه اى بر نظريه هاى كفتمان، مترجم: حسينعلى نوذرى، تهران: فرهنگ كَتمان

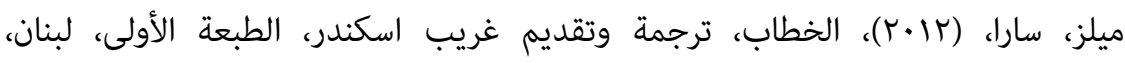

$$
\text { دارالكتب العلمية. }
$$
يارمحمدى، لطف الله، (זرباش)، كفتمان شناسى رايج وانتقادى، هاي اول، تهران: هرمس.

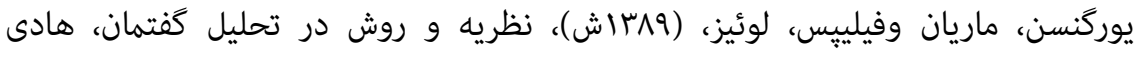

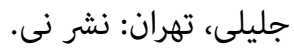




\section{References}

- The Holy Qur'an

- Aghagolzadeh, Firdows (2006), analysis of critical discourse, Tehran, scientific and cultural.

- Aghagolzadeh, Firdaws and the Others, (2007), "The Prevailing Trends in the Critical Analysis of Discourse, Journal of Language and Linguistics, Third Year, Issue 5.

- Ashori, Dariush, (1994) Poetry and Thought, Nashr publication, first edition.

- Ibn Manzur, Jamal Al-Din Muhammad bin Makram, (1905), Lisan ALArab, first volume, Qom: Literature of the Hawzeh.

- Bahram Pour, Shaaban Ali, (2000). introduction to discourse analysis, collection of discourse analysis, by Muhammad reza Tajik, first edition, Tehran: culture of discourse

- Bahram Pour, Shaabanali, (2000), Introduction to discourse analysis, discourse and discourse Articles Collections, Tehran.

- Hanafi, Hassan, (1998), Analysis of Arabic discourse, the third practical conference, Amman: University of Philadelphia.

- Jahangiri, Jahangir and others, (2000), language ability and Ideology in Norman Warklaf's approach, critical, theoretical. policy research, No.14, pp.57-82

- Rustampour, Roghayyeh and others (2012), «Analysis of political discourse at the morphological level in the poems of Samih Al-Qasim (A Comparison between poetry before and after the 1997 wars».

- Daylameh, Niko, (2013), Wisdom in the epistemology cal Structure of surah Al-Hujurat, journal of practical research for explanatory studies, fourth year, no. 13, pp,51-66

- Al-Okasha, Mahmoud, (2013), The linguistic (pragmatic) linguistic theory, The study of concepts, origination and principles, Cairo: Maktab al-Adab Publications.

- Azeddanlu, Hamid, (2001) Discourse and society, Tehran, Ney Publications.

- Fowler, Roger and others, (1990), Linguistics, Literary Criticism: Translated by Maryam Khuzan and Hussain Payandeh, First edition, Tehran: Nea.

- Fairclough, Norman, (2000), Analysis of critical discourse, Translators: Fatimah Shayesteh Biran and others, editors: Muhammad Nabawi, and Mehran Muhajir, First edition, Tehran: center for media studies and research. 
- Qera'ati Mohsen (2001), The interpretation of surah Al-Hujurat, Tehran, The cultural center of lessons from the Holy Qur'an.

- Kia, Ali Asghar, (2000), Theories and Foundation of developments in media research, journal of research and measurement, No.32, ninth year.

- Makarem Al-Shirazi, Nasser, (1997) Tafseer Al-Nemooneh, Tehran, Islamic books house.

- Muhammadi Ashnayi, Ali (2005), building religious society in the biography of the prophet, (Al-Fikr, Al-Taqrab), No 10, pp 19-40.

- Miqdadi, Bahram, (1999), The Culture of library terminology from Plato to the present, Fekreh rooz.

- Mac Dunnel, Dayan, (2001), An introduction to theories of discourse, translated by: Hussain Ali Nothari, Tehran: the of discourse.

- Mills, Sara, (2012), Discourse, Translated and curated by Gharib Alexander, first edition, Lebanon, Dar Al-Kotob Al-Elamiyeh.

- Nistani, Mahmoud, (2000), Analysis of critical discourse. work has escaped interpretation, clarification and position of the interpreter: analysis of critical discourse by wroclaw, center for media studies.

- Yarmohammadi, Lotf Allah, (2004) Common knowledge and critical speech, first edition, Tehran, Hermes.

- Jürtsen, Marianne and Phelps, Louise, (2011), Theory and method in discourse Hadi Jalili, Tehran, Nei publishes. 


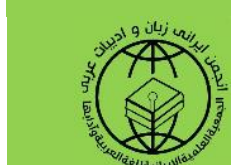

\section{مطالعات روايت شاناسـ عربـ \\ شايا جايى: + شو}

تحليل كفتمان روايى سوره حجرات براساس نظريه نورمن فركلاف

asvadi@khu.ac.ir

رايانامه:

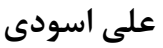

استاديار كروه زبان و ادبيات عربى دانشخاه خوارزمى، ايران، (نويسنده مسئول)

soud42_moz@khu.ac.ir رايانام:

سودابه مظفرى

mah.goharrostami@gmail.com

استاديار كروه زبان و ادبيات عربى دانشخاه خوارزمى، ايران رايانامه:

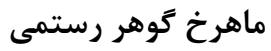

دانشجوى كارشناسى ارشد كروه زبان و ادبيات عربى، دانشكاه خوارزمى

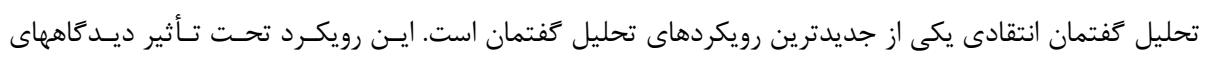

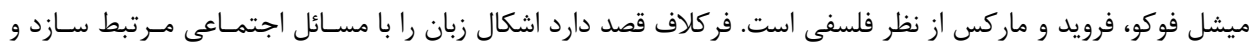

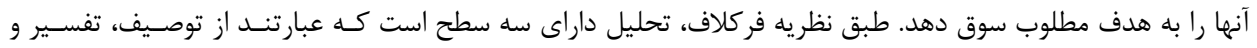

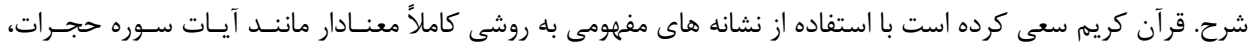

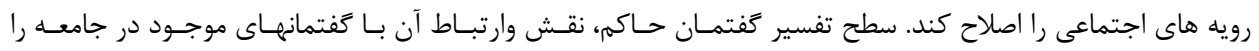

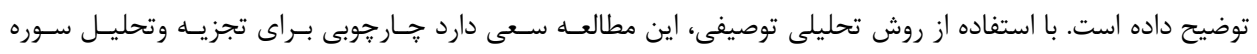

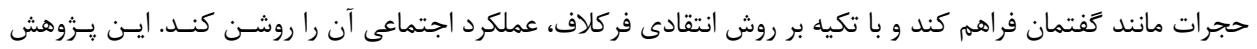

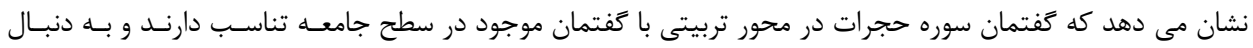
تبيين نظام ارزشى اسلامى هستند.

وازَّان كليدى: قرآن كريم، سوره حجرات، كفتمان، فركلاف، تحليل انتقادى، روايت شناسى عربى.

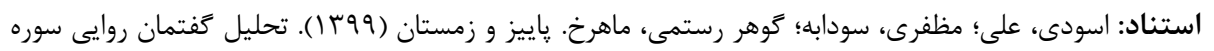

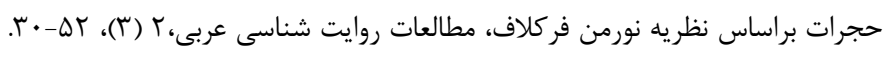

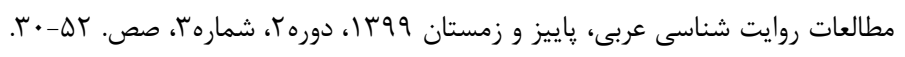

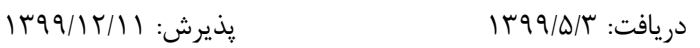

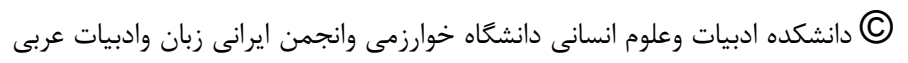

